\title{
Making European performance and impact assessment
}

\section{frameworks glocal [version 1; peer review: 1 approved, 1}

\section{approved with reservations]}

\author{
Ana M.P. Melo(D1,2, Sofia Oliveira (D1,3, Jorge S. Oliveira1,3, Corinne S. Martin(i)4, \\ Ricardo B. Leite (D) 1,3 \\ ${ }^{1}$ BioData.pt - Portuguese Infrastructure of Biological Data, Oeiras, Portugal \\ 2INESC ID - Instituto Nacional de Engenharias de Sistemas e Computadores - Investigação e Desenvolvimento, Lisboa, Portugal \\ 3Instituto Gulbenkian de Ciência, Oeiras, Portugal \\ ${ }^{4}$ ELIXIR Hub, 4. ELIXIR Hub, Hinxton, Cambridge, CB10 1SD, UK
}

V1 First published: 04 Mar 2022, 11(ELIXIR):278

https://doi.org/10.12688/f1000research.108804.1

Latest published: 02 Aug 2022, 11(ELIXIR):278

https://doi.org/10.12688/f1000research.108804.2

\begin{abstract}
Sustainability of research infrastructures (RIs) is a big challenge for funders, stakeholders and operators, and the development and adoption of adequate management tools is a major concern, namely tools for monitoring and evaluating their performance and impact. BioData.pt is the Portuguese Infrastructure of Biological and Portuguese node of the European Strategy Forum on Research Infrastructures "Landmark" ELIXIR. The foundations of this national research infrastructure were laid under the "Building BioData.pt" project, for four years. During this period, performance and impact indicators were collected and analysed under the light of international guidelines for assessing the performance and impact of European research infrastructures produced by the European Strategy Forum on Research Infrastructures, the Organisation for Economic Cooperation and Development and the EU-funded RI-PATHS project. The exercise shared herein showed that these frameworks can be adopted by national RIs, with the necessary adaptations, namely to reflect the national landscape and specificity of activities, and can be powerful tools in supporting the management of RIs.

"Not everything that counts can be counted, and not everything that can be counted, counts". Albert Einstein, Theoretical physicist and Nobel Prize winner
\end{abstract}

Keywords

biological data, FAIR, research management, open science, performance and impact indicators, research infrastructures, socioeconomic impact

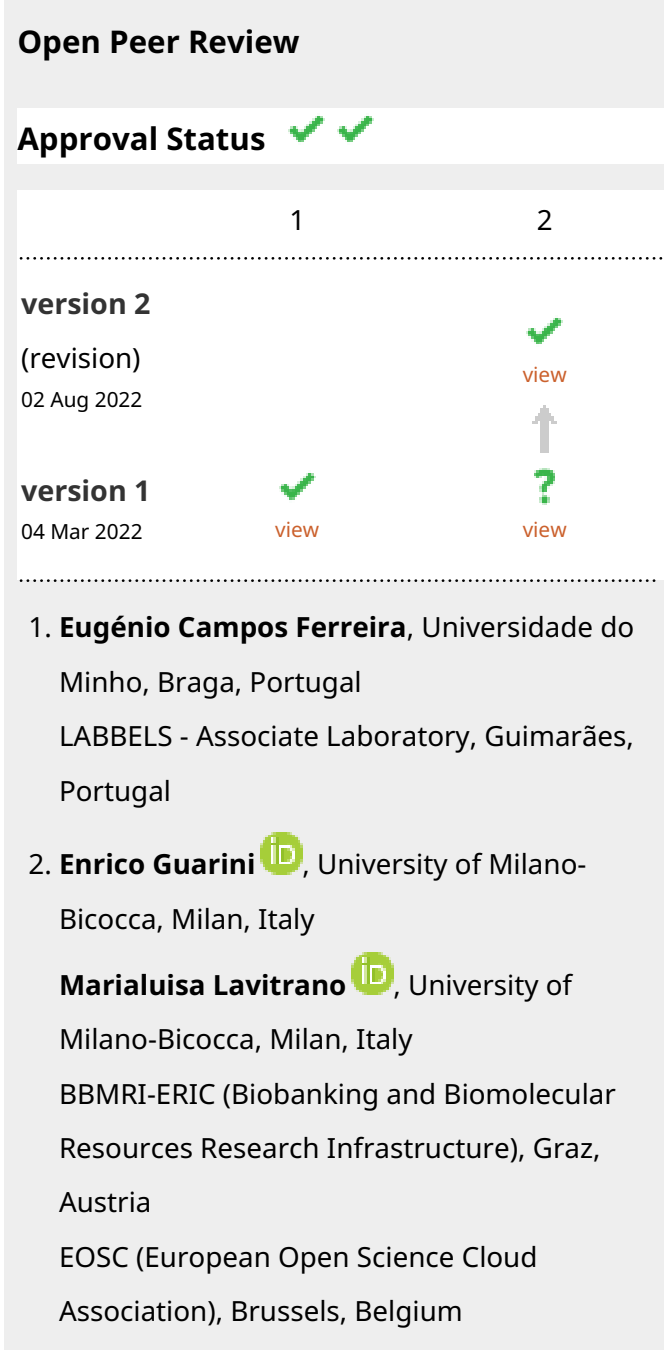


This article is included in the Research on

Any reports and responses or comments on the article can be found at the end of the article.

Research, Policy \& Culture gateway.

This article is included in the Bioinformatics

gateway.

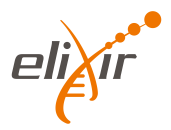

This article is included in the ELIXIR gateway.

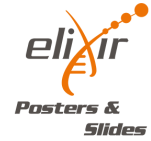

This article is included in the ELIXIR Posters and

Slides collection.

Corresponding author: Ana M.P. Melo (ana.portugal.melo@sapo.pt)

Author roles: Melo AMP: Conceptualization, Data Curation, Formal Analysis, Funding Acquisition, Investigation, Methodology, Project Administration, Resources, Supervision, Visualization, Writing - Original Draft Preparation, Writing - Review \& Editing; Oliveira S: Data Curation, Formal Analysis, Investigation, Methodology, Project Administration, Validation, Visualization, Writing - Original Draft Preparation; Oliveira JS: Visualization, Writing - Original Draft Preparation, Writing - Review \& Editing; Martin CS: Writing - Original Draft Preparation, Writing - Review \& Editing; Leite RB: Writing - Original Draft Preparation, Writing - Review \& Editing

Competing interests: No competing interests were disclosed.

Grant information: The work was funded by "Fundação para a Ciência e Tecnologia” (FCT) and PT2020, through the BioData.pt project (PINFRA/22231/2016), the European Union Horizon 2020 through ELIXIR-CONVERGE (871075), and the ELIXIR Strategic Implementation Study "Impact evaluation at Node-level - getting it done".

The funders had no role in study design, data collection and analysis, decision to publish, or preparation of the manuscript.

Copyright: ( $) 2022$ Melo AMP et al. This is an open access article distributed under the terms of the Creative Commons Attribution License, which permits unrestricted use, distribution, and reproduction in any medium, provided the original work is properly cited.

How to cite this article: Melo AMP, Oliveira S, Oliveira JS et al. Making European performance and impact assessment frameworks glocal [version 1; peer review: 1 approved, 1 approved with reservations] F1000Research 2022, 11(ELIXIR):278 https://doi.org/10.12688/f1000research.108804.1

First published: 04 Mar 2022, 11(ELIXIR):278 https://doi.org/10.12688/f1000research.108804.1 


\section{Introduction}

The long-term sustainability of Research Infrastructures (RIs) is of great importance to the European Strategic Forum on Research Infrastructures (ESFRI) and the European Union more broadly, as shown by calls for RIs to demonstrate their economic and wider benefit to society. ${ }^{1}$ For the Organisation for Economic Co-operation and Development (OECD), sustainability is also a major concern as RIs represent an increasingly large share of research investment by national governments. $^{2}$ As a result, recent years have seen the emergence of a number of frameworks (ESFRI, OECD and that developed by the EU-funded RI-PATHS project) to guide RIs in their journeys to demonstrate performance and impact, going beyond simply scientific impact, and considering public value more generally.

\section{Motivation}

BioData.pt is the Portuguese Infrastructure of Biological Data and the Portuguese node of ELIXIR. In this study, the goal was to consider three frameworks for impact and performance evaluation (ESFRI, OECD and RI-PATHS) in relation to existing indicators maintained by the BioData.pt project, from now on referred to as "Building BioData.pt", funded via the Portuguese state budget and European structural funds. From this, we expected to gain a more systematic, structured, and deeper understanding of the performance and impact of this national-level RI, and to use this new knowledge to inform its further development towards long-term sustainability. Beyond the qualitative assessment itself, this exercise aimed to document a process that may help national nodes of distributed European RIs to understand the impact of their activities, to inform stakeholders, policy makers and funders, as well as to improve their operations and increase their visibility, and overall prestige. In addition, it aimed to assess the relevance and adequacy of the indicators used by BioData.pt. It is expected that our findings, including lessons learned, will be useful to other similar public-funded RIs, which are often working with limited resources and do not have the means to fund repeated impact evaluations by specialized consultancies.

\section{Organization and historical path}

Although BioData.pt is the Portuguese Infrastructure of Biological Data and the Portuguese Node of the ESFRI Landmark ELIXIR (a pan-European research infrastructure for life science data, Ref. 3), it relies on fixed-term project funds to operate. A historical note of BioData.pt and the Portuguese Node of ELIXIR is depicted in Figure 1.

Since 2017, the development and early operation of BioData.pt have been funded through a $€ 2.7 \mathrm{M}$ project grant to last for four years, to lay the foundation of this RI. The "Building BioData.pt" project involved 11 beneficiaries and 81 participants, many of which providing in-kind expertise on computing, bioinformatics and data management to a range of endusers, as well as building and operating the infrastructure itself. Of the project budget, $33 \%$ was used to hire human resources and $57 \%$ to purchase equipment, mostly computing resources to assemble the nationally distributed computing

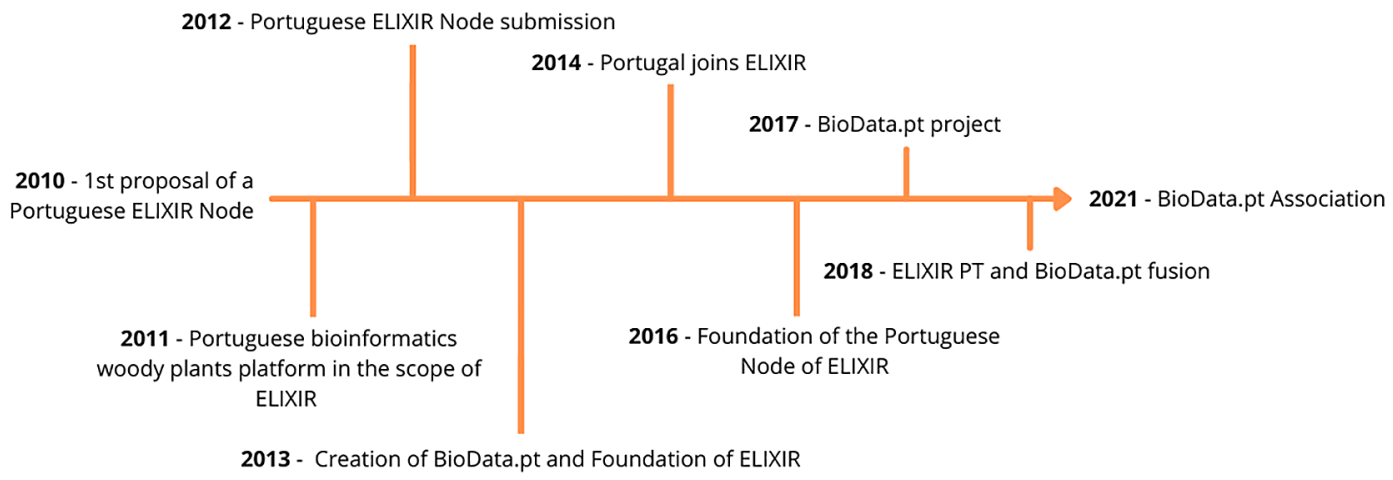

Figure 1. Historical path of the Portuguese Node of ELIXIR. In 2010, a Portuguese researcher from IGC (Instituto Gulbenkian de Ciência) at the European Bioinformatics Institute was challenged to participate in the onset of ELIXIR and create the Portuguese Node of this, yet to be, research infrastructure. In 2011, a first step was done, by creating the Portuguese bioinformatics woody plants platform followed by the creation of BioData.pt - Portuguese Biological Data Network, to operate the Portuguese Node of ELIXIR (ELIXIR PT), in 2013. In the same year, the ELIXIR, an intergovernmental organisation bringing together life science resources from across Europe, namely, databases, software tools, training materials, cloud storage and supercomputers, was founded. In 2014, the Foundation for Science and Technology, on behalf of the Portuguese Government, signed the ELIXIR Consortium Agreement, by which Portugal adhered to ELIXIR and, in 2016, a collaboration agreement between INESC-ID (Instituto de Engenharia de Sistemas e Computadores, Investigação e Desenvolvimento) and ELIXIR was signed, creating the Portuguese Node of this pan-European infrastructure. The merger between BioData.pt and ELIXIR PT was formalized in 2018 and, very recently, already in 2021, the BioData.pt Association was founded as the legal entity of this RI. 
Table 1. Working groups (WG) of the "Building BioData.pt" project, which was instrumental to the creation and early operation of the BioData.pt infrastructure.

\begin{tabular}{|l|l|l|}
\hline $\begin{array}{l}\text { Research } \\
\text { Communities }\end{array}$ & Support to Research Communities & Industry Engagement \\
\hline WG1 - Plants & WG6 - Common Infrastructure & WG8 - Industry \& Entrepreneurship \\
\hline WG2 - Marine Resources & WG7 - Training & \\
\hline WG3 - Systems biology & WG3 - Systems biology & \\
\hline WG4 - Neurosciences & WG10 - Project Management \& Dissemination & \\
\hline WG5 - Yeastract & & \\
\hline
\end{tabular}

infrastructure. The remainder was used in the adaptation of buildings to host the computing infrastructure or to deliver training. "Building BioData.pt" was structured as shown in Table 1.

\section{Methods}

Based on the simplified RI-PATHS approach, which classifies indicator types in activity (concrete activities to be carried out within the scope of the project, visible to the public and under full control of the organization), outcome (short-term direct results of each activity, not under direct control of the organization) and impact (transformative effects of the activity on its target audience and beyond, in the mid to long term), ${ }^{4}$ a "BioData.pt Monitoring and Evaluation Matrix" (B-MEM) (Figure 2, Ref. 5) and supporting guidelines were developed to facilitate the onset of evaluation processes, by the BioData.pt infrastructure. This simple and participatory approach allowed project managers to view and document, for the first time, the 10 working groups (or work packages) (Table 1) of "Building BioData.pt" in terms of activities, outcomes and impact, and align these with the overarching objectives of the project. In a second stage, the existing "Building BioData.pt" indicators, which had been maintained during the four years of grant execution, were categorized as activity, outcome and impact indicators, and assigned to the most relevant RI-PATHS impact area.

Each existing "Building BioData.pt" indicator, which could be quantitative or qualitative by nature, was documented and cross-checked against those compiled by the RI-PATHS project, and the OECD and ESFRI frameworks.

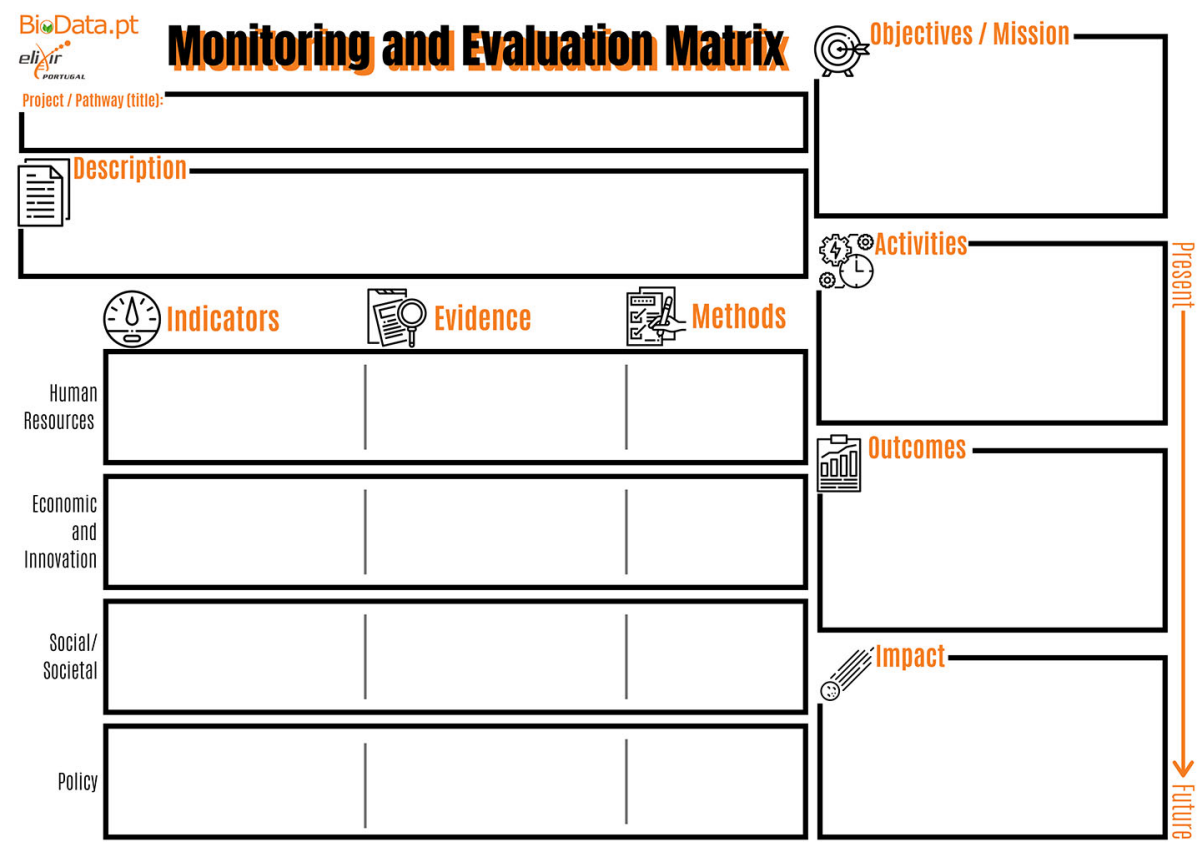

Figure 2. BioData.pt Monitoring and Evaluation Matrix. This matrix, internally developed during the BioData.pt project, was used to understand and document project working groups in terms of activities, outcomes and impact. 
Finally, the "Building BioData.pt" indicators were assessed against several sets of strategic objectives relevant to research infrastructures and their work: those of BioData.pt (as an organization), those of the current ELIXIR Scientific Programme, ${ }^{6}$ those of the Portuguese National Roadmap of Research Infrastructures, ${ }^{7}$ those of EOSC ${ }^{8}$ and, finally, those of the United Nations Sustainable Development Goals. ${ }^{9}$ This was done to gain insights into the relevance of BioData.pt in these broader contexts.

A visualization method was used to better document the relevance of the retrieved indicators, considering the national context, and the global environment of BioData.pt mission. A stacked column chart was generated entirely using the Rstudio software version 2021.09.0.351 and ggplot2 version 3.3.5, ${ }^{10}$ specifically using the ggplot() function, due to the complexity of the graphic. The fct_reorder() function of forcats version 0.5 .1 was used to reorder indicators according to their relevance, in decreasing order.

\section{Implementation and impact analysis}

The first step was the description of the "Building BioData.pt" project working groups, in terms of activities, outcomes and impact, and their alignment with its two overarching objectives, using the BioData.pt Impact Assessment Matrix (B-MEM) and the respective guidelines. Working groups (WG) 1 to 5 were dedicated to domain specific activities which, overall, aimed to build the BioData.pt Research Communities, and their expected outcomes were data curation, integration and availability for domain-specific areas with impact in enhancing the quality of scientific research by promoting the FAIR principles. The global activity of WGs 6, 7, 9 and 10 was to set up the Support to Research Communities, having three outcome/impact lines: 1) a fully available computational infrastructure for data analysis/ better and more extensive computing resources; 2) promotion of capacity-building in bioinformatics and research data management in the national research community/improved research efficiency \& effectiveness and human capital; and 3) overall management of RI and operation of the Portuguese Node of ELIXIR/strengthened RI long-term sustainability. Both "Research Communities" and "Support to Research Communities" were developed under the objective "Strengthening research, technological development and innovation". The second objective "Enhancing research knowledge transfer from academy to industry" was served by the activity Industry \& Entrepreneurship, developed by WG8, delivering promotion of knowledge transfer to industry to bring an added value to companies' data and an industrial ecosystem of companies aware/beneficiary of bioinformatics and research data management as outcome and impact, respectively.

Yet with the help of the B-MEM, the "Building BioData.pt" project and Infrastructure reports were mined for indicators that would relate to those compiled by the ESFRI, OECD and RI-PATHS frameworks. Table 2 shows one example of this implementation, performed for the activity "Research Communities", in relation to RI-PATHS. In detail, for this activity, we were able to find indicators of two types, activity and outcome, distinctly distributed by three of four impact areas, Human Resources, Economic and Innovation and Societal/Social. For each type of indicator identified, the indicator itself, the evidence for confirmation and method for description is listed. For instance, under the objective "Strengthening research, technological development and innovation", in the activity "Research Communities", the activity indicator Number of publications is identified by direct evidence (e.g., from Web of Science) and the method for collecting evidence is counting the number of publications. The full dataset of BioData.pt project indicators classified following the RI-PATHS approach can be accessed. ${ }^{11}$

This exercise was repeated using the impact assessment frameworks of ESFRI and OECD. These approaches cover more explicitly the so-called scientific impact, of which some indicators, like Number of publications and Number of Citations, are also covered in the Human Resources area of the RI-PATHS approach.

A summary of RI-PATHS' indicator types produced by "Building BioData.pt" (Table 3) shows that the different activities of the project, "Research Communities", "Support to Research Communities" and "Industry and Entrepreneurship", encompassing its 10 working groups had impact in all four RI-PATHS areas, namely, Human Resources, Economic and Innovation, Social/Societal and Policy, the working groups that provide "Support to Research Communities" having the broader socio-economic impact.

The indicators of "Building BioData.pt" identified in the ESFRI list corroborated the previous finding that the activities with broader impact were those dedicated to the "Support of Research Communities" (Table 4). The detailed information for this exercise is available for consultation. ${ }^{11}$ In addition, "Building BioData.pt" generated indicators for all ESFRI's areas and covered all indicators except number 14 (number of publicly available data sets used externally).

The analysis of "Building BioData.pt" indicators using the OECD framework (Table 5) also corroborated the broad impact of the project, by retrieving indicators for all impact areas. In this case, the scientific impact produced by the 


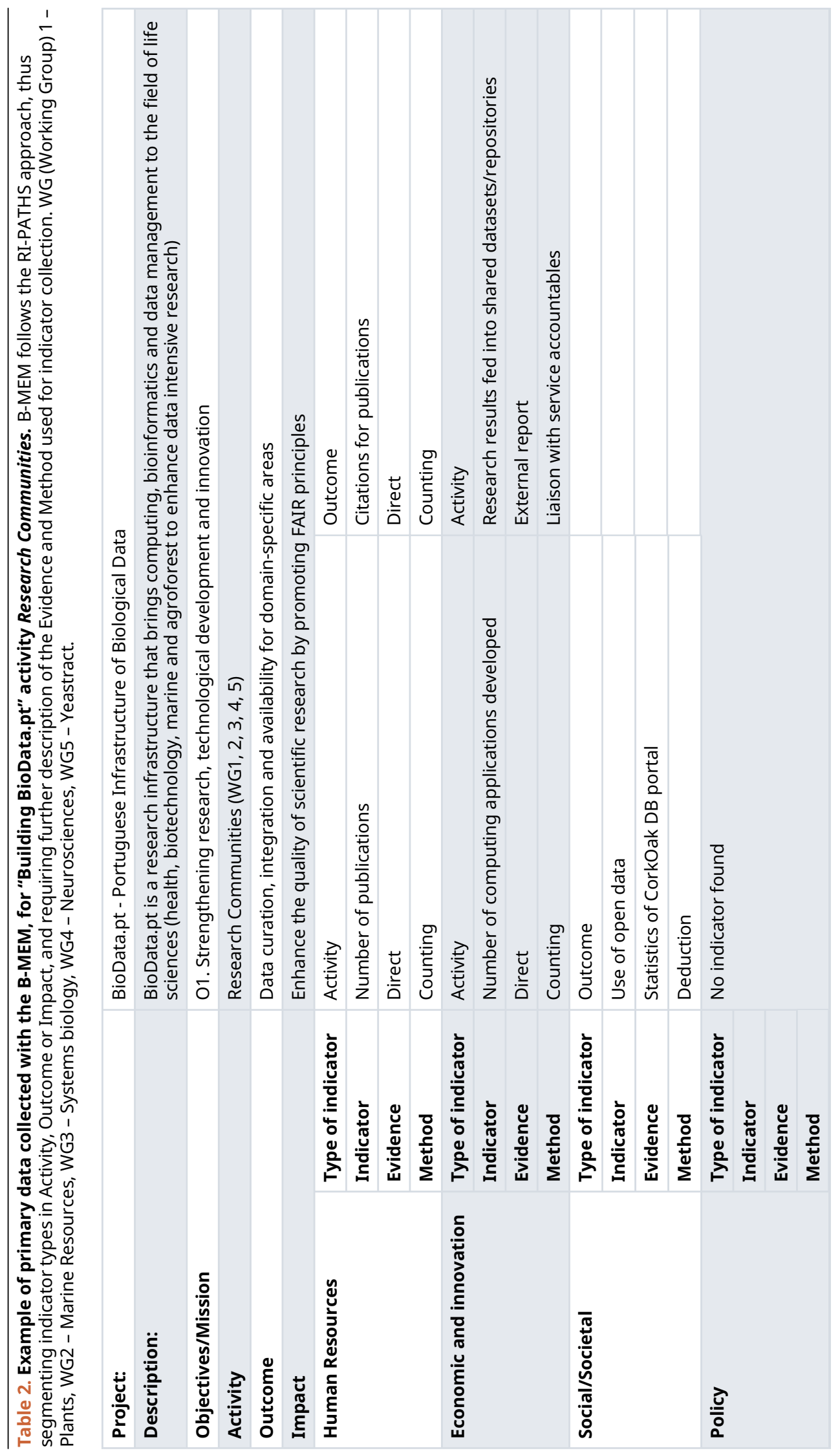




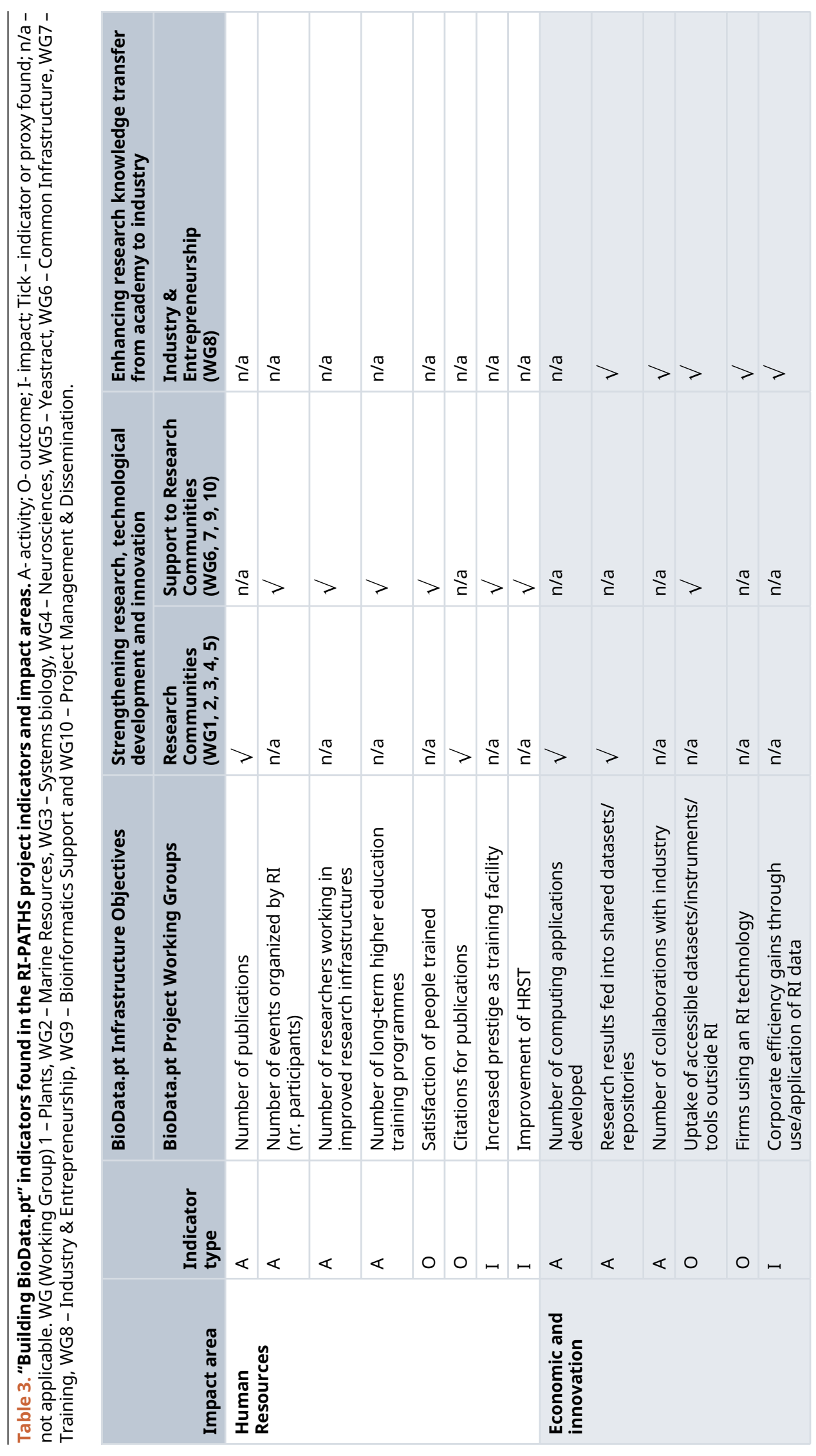




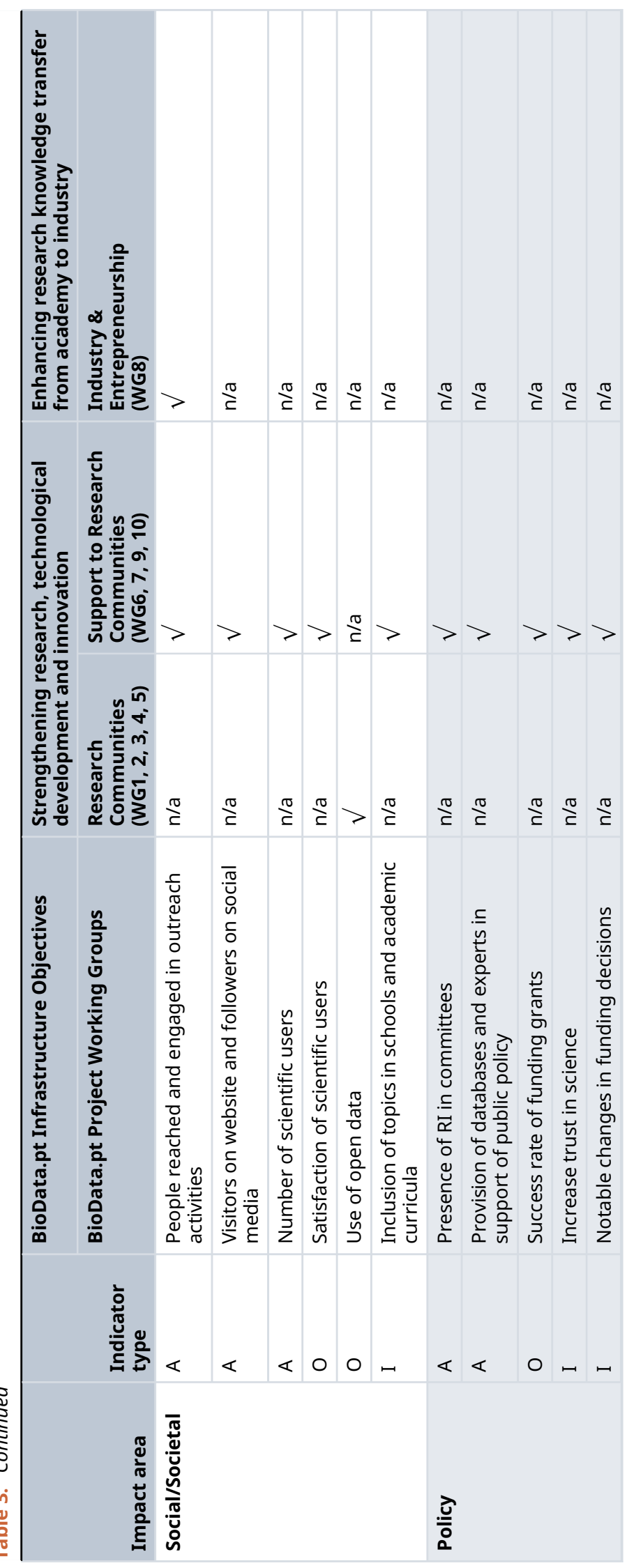




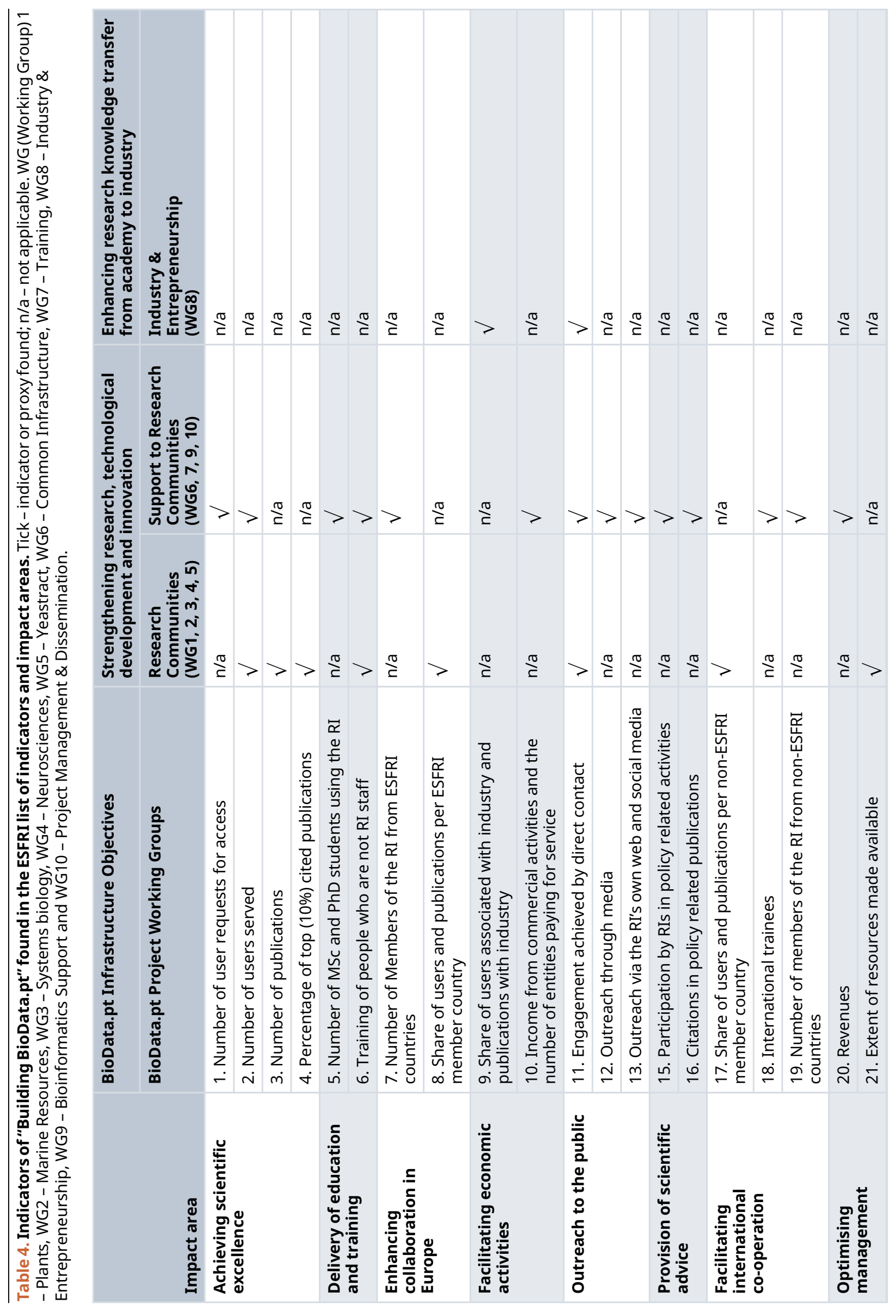




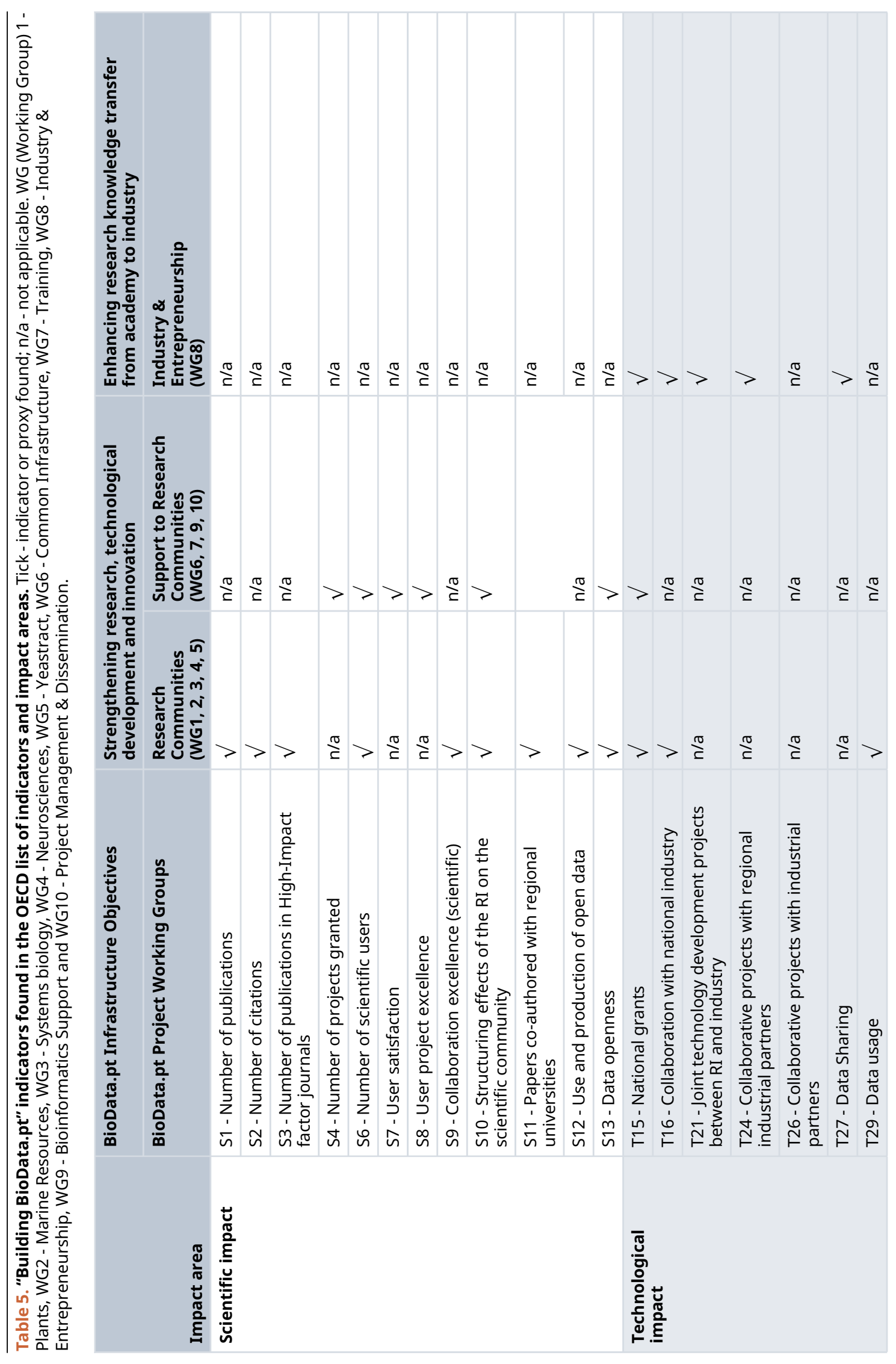




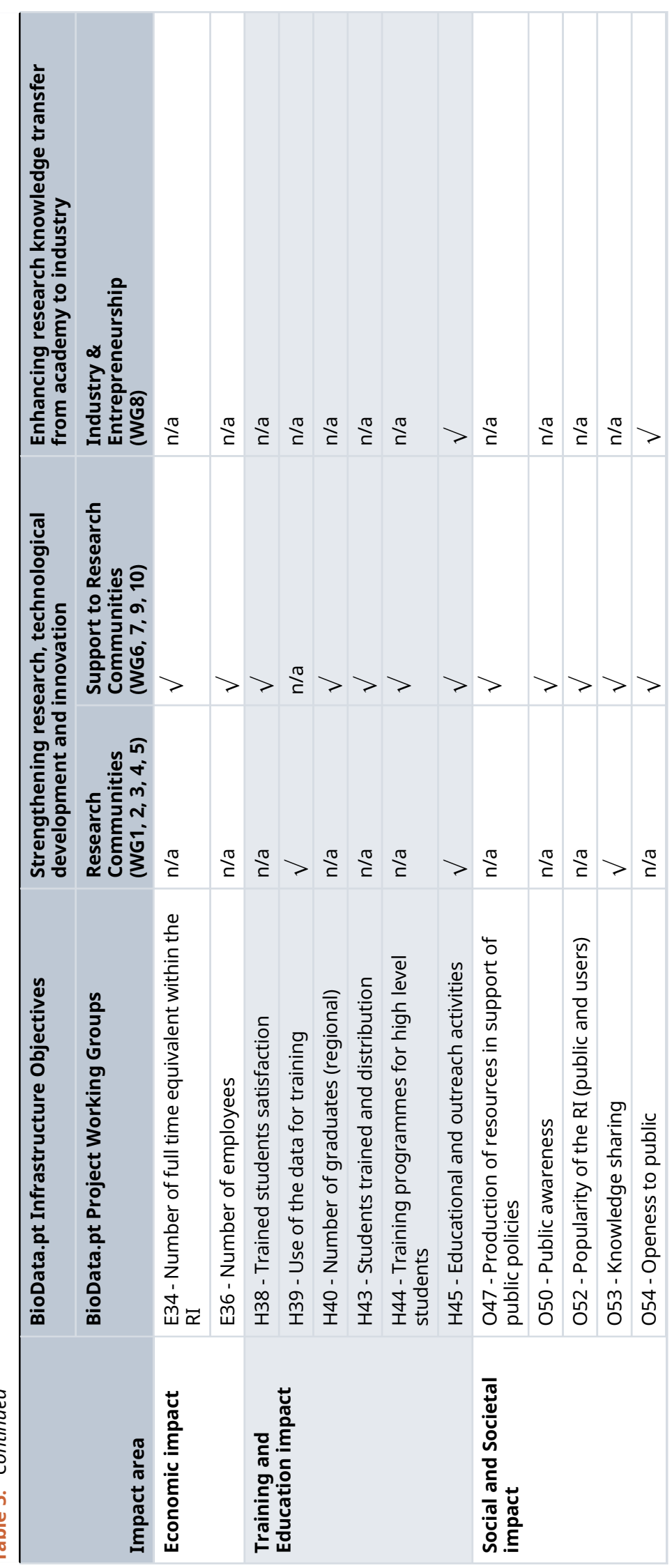




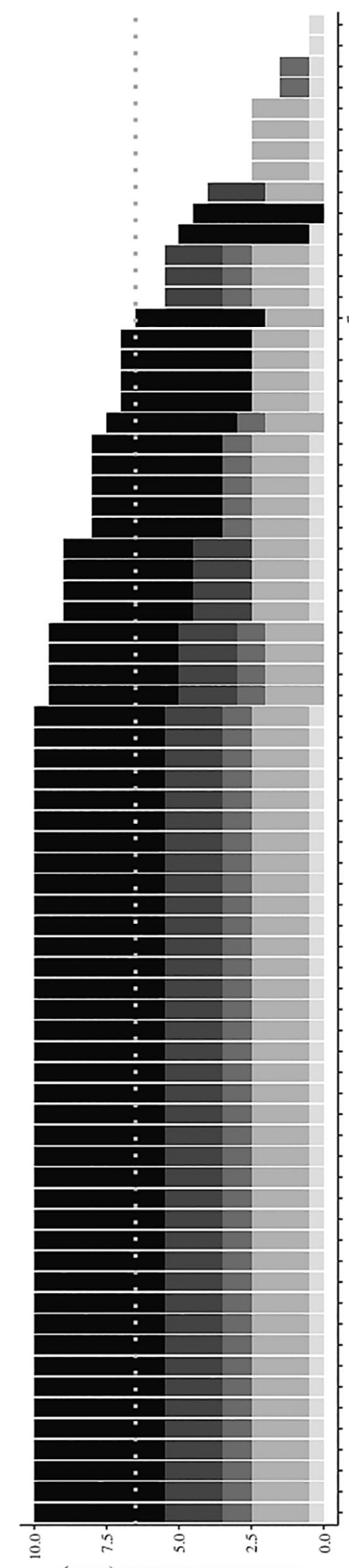

sətน

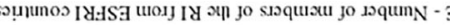

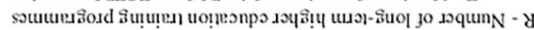

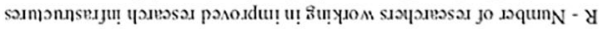

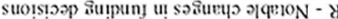

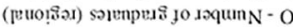

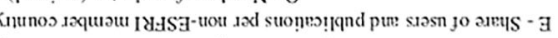

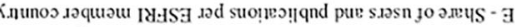

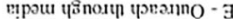

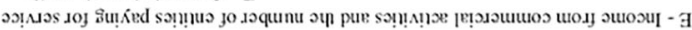

sosiopltue jo JoqunN - O

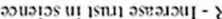

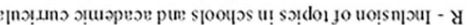

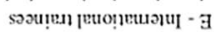

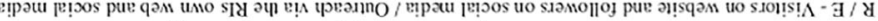

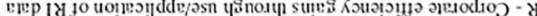

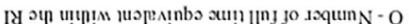

sonuosoy - a

ssaose dog sisonbad dasn jo dequn $\mathrm{N}$ - -

suolne?

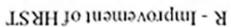

som!s.s.

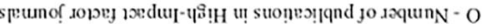

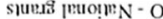

suoṇm!!

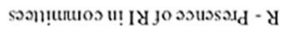

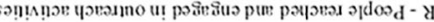

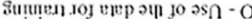

posiss siasn jo roquin -3

घep trado yo

घe

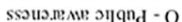

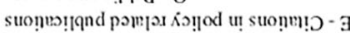

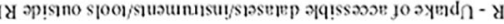

stues Supunj jo oje ssoons - y

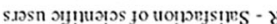

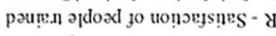

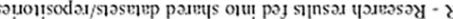

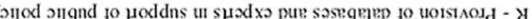

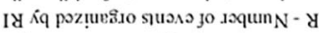

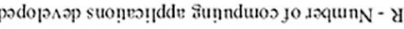

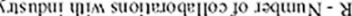

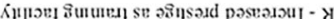

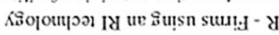

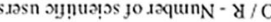

suopis! !qnd jo dequn $\mathrm{N}-\mathrm{y} / \mathrm{g} / \mathrm{O}$

uolpogyspes $10 \mathrm{~s} \Omega$ -

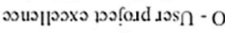

ร)

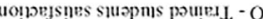

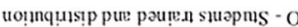

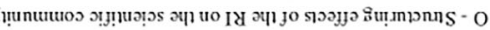

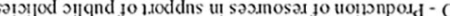

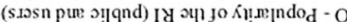

ग!

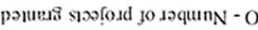

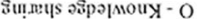

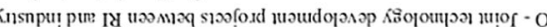

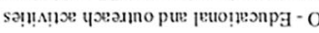

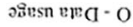

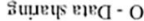

ssouudo rip:a - 0

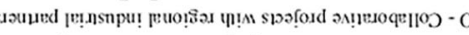

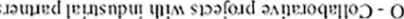

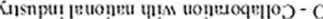

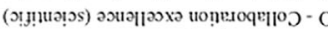

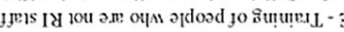

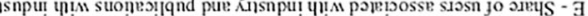

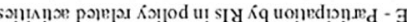

I

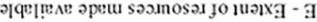

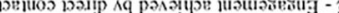

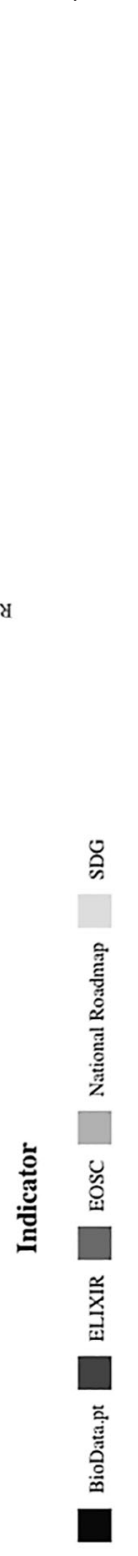

롱 
activities of "Research Communities" assumes particular relevance. Nonetheless, as for the previous frameworks, the activities related to "Support to Research Communities" have a wider impact. The full dataset of this analysis can be consulted. $^{11}$

The indicators generated by "Industry and Entrepreneurship" activities could find matches or proxies in the lists of the three impact assessment approaches, with greater emphasis, as expected, in the Economic and Innovation impact areas, enriching the project with a translational dimension.

Overall, this analysis showed that the activities carried out to accomplish the "Building BioData.pt" overarching objectives of "Strengthening research, technological development and innovation" and "Enhancing research knowledge transfer from academy to industry" covered the broad range of impact areas foreseen for European Research Infrastructures. This not only puts this RI of the National Roadmap aligned with sibling international counterparts, but also suggests that BioData.pt is well aligned with ELIXIR, bringing to the national scientific system the state-of-the-art topics of computing, bioinformatics and data management, addressed by this ESFRI Landmark.

Finally, the relevance of the retrieved indicators was ascertained, considering the national context and the global environment of the BioData.pt mission. Arbitrary units (A.U.) were attributed to the alignment of each indicator with the objectives/goals of the BioData.pt (4.5 A.U.), ELIXIR (2 A.U.), National Roadmap of Research Infrastructures (2 A.U.), EOSC (1 A.U.) and the Sustainable Development Goals - SDG (0.5 A.U.). A cutoff was established at 6.5 A.U., a score that could only be reached if an indicator matched BioData.pt goals and, at least, those of ELIXIR or the National Roadmap of Research Infrastructures, to which BioData.pt is bound by a formal relationship. Alignment with EOSC and SDG was sought to assess the chosen indicators in agreement with the main European trends in open science and the goals for global development, respectively (Figure 3). The full dataset of this analysis can be consulted. ${ }^{12}$

\section{Discussion}

Of the 102 indicators compiled as potentially relevant to RIs by the RI-PATHS project, 25 indicators were monitored during "Building BioData.pt", scattered in all impact areas, suggesting the broad socio-economic impact of BioData.pt. RI-PATHS also proposes a set of pathways that should be taken into consideration when assessing the socio-economic impact of specific project activities. For instance, pathways 5 - Learning and training by using RI facilities and services, 9 - Provision of specifically curated/edited data, and 11 - Creating and shaping scientific networks and communities could be applied in the monitoring the impact of BioData.pt training activities (e.g., "Ready for BioData Management?"), the CorkOak DB portal ${ }^{13}$ and the consolidation of our Communities and Platforms, in a multidisciplinary network to identify gaps in computing data management and bioinformatics for the life sciences and build solutions. In these cases, around 50\% alignment with the primary indicators of each referred pathway was observed, while only $25 \%$ alignment was detected when all BioData.pt project indicators were compared with the overall indicators list. These findings emphasize the need to adjust global performance and impact indicators to the particular context of a national project (e.g., with a wide scope that covered simultaneously Enabling Science, Problem-Solving, and Science and Society, in the case of the establishment of a national RI) or to a particular activity with a narrower scope (e.g., a training program, a community, a data portal).

Of the 21 indicators compiled by the ESFRI framework, 20 were monitored by "Building BioData.pt". The missing indicator, Number of publicly available data sets used externally, relates to the optimisation of data use and is a relevant indicator for a RI like BioData.pt. Although BioData.pt has publicly available datasets (e.g., Pheno and CorkOakDB ${ }^{13}$ ), it does not currently maintain indicators to demonstrate how these are being used externally. This difficulty also intricates with the fact that there is still a long way to go in the formal acknowledgement of RI services by its users, which is harder when the goods provided are intangible and sometimes provided by third parties. In the future, this topic should be addressed by putting in place a tracking system.

Finally, out of the 58 indicators compiled by the OECD framework, 32 were monitored by "Building BioData.pt", 18 belonging to Scientific Impact and Training and Education, emphasizing the importance of these areas into BioData.pt.

The three frameworks considered in this study were comprehensive enough to accommodate all indicators maintained during "Building BioData.pt", in spite of the fact that these were tailored according, for instance, to its specific national context, mission and role as a national node of a European RI. ${ }^{14}$ In addition, considering absent indicators may also prove useful to bring our attention to untracked activities that are relevant to the mission of a RI.

The vast majority of the ESFRI, OECD and RI-PATHS indicators identified in Building BioData.pt surpassed the 6.5 A.U. in our scoring exercise, indicating that, this project was well aligned with current thinking around the performance 
and impact of RIs. This also reflects the natural integration of BioData.pt in the European and Portuguese research landscape. Furthermore, alignment with the EOSC goals was also very frequently observed underlining the commitment of BioData.pt with the best practices of FAIR data management and open science. It was interesting to observe the overlap between BioData.pt and SDG objectives, suggesting that national RIs, as likely their European counterparts, can give a valuable contribution to global sustainable development, and are thus a public good. Below the cutoff, three indicators contributing to the strategic objectives of the BioData.pt infrastructure were identified that did not align with the priorities of ELIXIR or the National RoadMap of Research Infrastructures. These were the number of employees and the income from commercial activities and the number of entities paying for service. Although these indicators are not directly related to the mission of BioData.pt, they may assume a very relevant role for its long-term sustainability and thus, perhaps both the National Roadmap for Research Infrastructures and ELIXIR would like to consider this information when revising their priorities.

\section{Final remarks}

The monitoring of RIs performance and impact through indicators can be powerful in strategic management not only for continuous monitoring but also to inform future steps at the level of funders, optimization of processes and visibility by users and citizens. ${ }^{15,16}$ Although highly qualified consultants are available to provide such service, national RIs are typically underfunded, and thus cannot support the cost. It is thus critical to establish simple and participatory methods to be implemented by the RI staff with oversight from the management team.

From this study, it is clear that the approaches developed by ESFRI, OECD and RI-PATHS are very useful and adaptable to the national context. It is also clear that special attention should be given to the national and thematic context of the activities under assessment.

Overall, there is a strong alignment of "Building BioData.pt" with the mission of a research infrastructure as foreseen by ESFRI. The major flaw recognised under this study, respecting the difficulty to control external use and acknowledgement of RI assets, such us datasets, may need a collective solution to be addressed in the future.

This exercise was done backwards to provide lessons for the future, where ex ante the areas where impact aims to be achieved, the different types indicators for each activity to be collected, as well as the methods for capturing should be documented.

In this scope, the methodology used to assess the relevance of the indicators maintained during "Building BioData.pt" (Figure 3) can be useful to adapt the selection of indicators to a specific context, taking into account the mission and goals of the RI, and also those of national and international organizations and global initiatives composing the landscape where the RI develops its work and aims to have impact. To successfully assess performance and impact of RIs it is also very important to set up processes where the staff should be involved already from the planning stage, such as the BioData.pt monitoring and evaluation matrix (Figure 2).

\section{Data availability}

Underlying data

Zenodo: Mapping Building BioData.pt Indicators against the performance and impact assessment frameworks for research infrastructures of OECD, ESFRI and RI-PATHS project, https://doi.org/10.5281/zenodo.5828310. ${ }^{11}$

Zenodo: Relevance of "Building BioData.pt" indicators identified in ESFRI (E), OECD (O) and RI-PATHS (R) impact assessment frameworks, https://doi.org/10.5281/zenodo.5828295. ${ }^{12}$

Data are available under the terms of the Creative Commons Attribution 4.0 International license (CC-BY 4.0).

References

1. European Strategy Forum on Research Infrastructures Long-Term Sustainability Working Group: Long-Term Sustainability of Research Infrastructures. Dipartimento di Fisica - Università degli Studi di Milano; October 2017. 978-88-901562-8-1. Reference Source

2. Directorate for Science, Technology and Innovation, Committee for Scientific and Technological Policy: Strengthening the
Effectiveness and Sustainability of International Research Infrastructures. Organisation for Economic Co-operation and Development. 2017. Reference Source

3. Harrow J, Drysdale R, Smith A, et al.: ELIXIR: providing a sustainable infrastructure for life science data at European 
scale. Bioinformatics. 2021; 37(16): 2506-2511 PubMed Abstract | Publisher Full Text

4. Helman A, Barberis M, Vignetti S, et al.: Deliverable 5.1. SocioEconomic Impact Assessment Framework. Research Infrastructure imPact Assessment paTHwayS (RI-PATHS). European Union's Coordination and Support Action project (contract 777563). 2020; 70 pp.

Reference Source

5. Val SB, Faria D, Contreiras SM, et al.: Impact Assessment of Node Activities Canvas ELIXIR Portugal. Figshare. 2020. Publisher Full Text

6. Heads of Nodes, Platform and Community Leaders, Technical and Training Coordinators and members of the various Working Groups: ELIXIR 2019-23 Scientific Programme. 2018. Reference Source

7. Fundação para a Ciência e a Tecnologia: Portuguese Roadmap of the Research Infrastructures. 2020. 978-972-667-357-6. Reference Source

8. European Commission, Directorate-General for Research and Innovation: European Open Science Cloud (EOSC) strategic implementation plan. Publications Office; 2019. Publisher Full Text

9. United Nations: Transforming Our World: The $\mathbf{2 0 3 0}$ Agenda for Sustainable Development. Reference Source

10. Wickham H: ggplot2: Elegant Graphics for Data Analysis. New York: Springer-Verlag; 2016. 978-3-319-24277-4.
11. Melo AMP, Oliveira S, Oliveira J, et al.: Mapping Building BioData.pt Indicators against the performance and impact assessment frameworks for research infrastructures of OECD, ESFRI and RI-PATHS project. 2022.

Publisher Full Text

12. Melo AMP, Oliveira S, Oliveira J, et al.: Relevance of "Building BioData.pt" indicators identified in ESFRI (E), OECD (O) and RI-PATHS (R) impact assessment frameworks. 2022. Publisher Full Text

13. Arias-Baldrich C, Silva MC, et al.: CorkOakDB - The Cork Oak Genome Database Portal. Database. 2020; 2020. PubMed Abstract | Publisher Full Text

14. Reid A, Griniece E, Angelis J: Evaluating and Monitoring the SocioEconomic Impact of Investment in Research Infrastructures. 2015 Publisher Full Text

15. Turpen PB, Hockberger PE, Meyn SM, et al.; Metrics for Success: Strategies for Enabling Core Facility Performance and Assessing Outcomes. J. Biomol. Tech. 2016; 27(1): 25-39. PubMed Abstract | Publisher Full Text

16. Martin C, Repo S, Márquez J, et al.: Demonstrating public value to funders and other stakeholders-the journey of ELIXIR, a virtual and distributed research infrastructure for life science data. Ann. Public Cooperative Econ. 2021; 92: 497-510.

Publisher Full Text 


\section{Open Peer Review}

\section{Current Peer Review Status:}

\section{Version 1}

Reviewer Report 06 April 2022

https://doi.org/10.5256/f1000research.120233.r126307

(C) 2022 Guarini E et al. This is an open access peer review report distributed under the terms of the Creative Commons Attribution License, which permits unrestricted use, distribution, and reproduction in any medium, provided the original work is properly cited.

\section{Enrico Guarini}

Department of Business and Law, University of Milano-Bicocca, Milan, Italy

\section{Marialuisa Lavitrano}

1 School of Medicine and Surgery, University of Milano-Bicocca, Milan, Italy

2 BBMRI-ERIC (Biobanking and Biomolecular Resources Research Infrastructure), Graz, Austria

3 EOSC (European Open Science Cloud Association), Brussels, Belgium

This paper examines how the international frameworks developed for the monitoring and evaluation of performance and impact of research infrastructures (RIs) can be adopted by national RIs to support its management. This is done by presenting the results of a four-year project of collecting and analyzing performance indicators carried out during the development of the Portuguese Infrastructure of Biological Data (BioData.pt) as the national node of an international RI (ELIXIR). The authors focus on three performance measurement frameworks developed for RIs (ESFRI, OECD, and RI-PATHS) and empirically assess how the combination of suggested performance indicators can be applied at the operational level to assess the impact of the organization. Within this perspective, the authors aim to contribute to developing useful tools for RI management.

The article is clear and well written, however, it needs improvement. Our main point is that the authors could better discuss the management implications of their findings.

Below we present our main points and suggestions:

Firstly, the authors focus from the beginning on the process of development of the national node - the 'Building BioData.pt' project - paying scarce attention in the Discussion section to the operational phase, for example, which indicators can also be relevant for the permanent organization/node itself rather than for the project phases. We would encourage the authors to clarify this from the beginning since the abstract seems to propose general implications for RI management. We would like to see some reflections at a general level (maybe also in the conclusions).

One major point that needs further specification is, first of all, the adaptability of the three frameworks at the national node level. The authors present a list of 77 retrieved indicators 
out of 181 from the three frameworks. It is still not clear why some indicators were more relevant than others, and why many of the proposed indicators were excluded. The authors need to better clarify if this was related to the need to adjust the impact indicators to the context of the project, to the construction stage of the RI, to the national goals/strategy, or to data availability. Thus, the authors need to discuss in more detail how the case studied and the findings might affect the generalisability of the results. In other words, the issue of adaptation from 'global' to 'local' needs to be better addressed (in the discussion/conclusion).

Another point that requires further specification is not only the relation between the indicators and the national context/strategy but also the managerial implications of collecting and using these indicators. Apart from the issue of collecting data from third parties, we think that the process of staff engagement in the measurement process should be discussed further. For example, the authors could consider the opportunity to provide more insights into how the participatory approach was conducted and received by the staff. The engagement of team members in performance measurement could be an important aspect to be emphasised as a management implication.

In the 'Methods section,' the authors report the results of scoring of indicators to assess their alignment with national and international goals. No information is provided about the method and reliability of the scoring process. Moreover, it is not clarified what is meant here with the concept of 'alignment'.

Since the article focuses on RIs, we would encourage the authors to include it in the title.

Minor comments:

Table 1. To improve readability, we would suggest adding a label 'Activity' to refer to "Research Communities", "Support to Research Communities", and "Industry engagement", and a label 'Objectives' to refer to "Strengthening research, technological development and innovation" (WGs 1, 2, 3, 4, 5, 6, 7, 9, 10), and to "Enhancing research knowledge transfer from academy to industry" (WG8).

Table 1. WG9 is missing.

Table 1. The activity "Industry Engagement" is mentioned as "Industry and Entrepreneurship" in the 'Implementation and impact analysis' section.

Methods. Clarify the years during which the measurement process was conducted.

Is the topic of the opinion article discussed accurately in the context of the current literature?

Yes

Are all factual statements correct and adequately supported by citations? Yes

Are arguments sufficiently supported by evidence from the published literature? 
Yes

Are the conclusions drawn balanced and justified on the basis of the presented arguments? Partly

Competing Interests: No competing interests were disclosed.

Reviewer Expertise: Financial management and governance in government and not-for-profit settings; Performance Management; Management of Research Infrastructures

We confirm that we have read this submission and believe that we have an appropriate level of expertise to confirm that it is of an acceptable scientific standard, however we have significant reservations, as outlined above.

Author Response 28 Jul 2022

Ana Melo

Dear Drs Lavitrano and Guarini,

The authors have read thoroughly read your appreciation of this article and proceeded to the necessary modifications. We are very grateful for your analysis and think that it helped us to improve the quality of the article.

In detail:

Firstly, the authors focus from the beginning on the process of development of the national node - the 'Building BioData.pt' project - paying scarce attention in the Discussion section to the operational phase, for example, which indicators can also be relevant for the permanent organization/node itself rather than for the project phases. We would encourage the authors to clarify this from the beginning since the abstract seems to propose general implications for RI management. We would like to see some reflections at a general level (maybe also in the conclusions).

A paragraph was added to the discussion to suggest a set of indicators that can be relevant for the operational stage of BioData.pt, as a mature infrastructure.

One major point that needs further specification is, first of all, the adaptability of the three frameworks at the national node level. The authors present a list of 77 retrieved indicators out of 181 from the three frameworks. It is still not clear why some indicators were more relevant than others, and why many of the proposed indicators were excluded. The authors need to better clarify if this was related to the need to adjust the impact indicators to the context of the project, to the construction stage of the RI, to the national goals/strategy, or to data availability. Thus, the authors need to discuss in more detail how the case studied and the findings might affect the generalisability of the results. In other words, the issue of adaptation from 'global' to 'local' needs to be better addressed (in the discussion/conclusion).

The discussion was reformulated to address and clarify the adaptability of the frameworks to the national node level, and the criteria to discriminate and attribute relevance to the indicators. Overall, the discussion section is now more detailed and emphasises the issue of adaptation from 'global' to 'local' needs. 
Another point that requires further specification is not only the relation between the indicators and the national context/strategy but also the managerial implications of collecting and using these indicators. Apart from the issue of collecting data from third parties, we think that the process of staff engagement in the measurement process should be discussed further. For example, the authors could consider the opportunity to provide more insights into how the participatory approach was conducted and received by the staff. The engagement of team members in performance measurement could be an important aspect to be emphasised as a management implication.

The managerial implications of using the selected indicators are described, and the process of staff engagement is documented including recommendations for future assessments. In the 'Methods section,' the authors report the results of scoring of indicators to assess their alignment with national and international goals. No information is provided about the method and reliability of the scoring process. Moreover, it is not clarified what is meant here with the concept of 'alignment'.

The methods section was modified to clarify the concept of "alignment" and further information about the method and scoring process was included.

Since the article focuses on RIs, we would encourage the authors to include it in the title.

The title was modified accordingly.

Minor comments:

Table 1. To improve readability, we would suggest adding a label 'Activity' to refer to "Research Communities", "Support to Research Communities", and "Industry engagement", and a label 'Objectives' to refer to "Strengthening research, technological development and innovation" (WGs 1, 2, 3, 4, 5, 6, 7, 9, 10), and to "Enhancing research knowledge transfer from academy to industry" (WG8).

The table was modified accordingly.

Table 1. WG9 is missing.

The table was modified accordingly.

Table 1. The activity "Industry Engagement" is mentioned as "Industry and Entrepreneurship" in the 'Implementation and impact analysis' section.

The table was modified accordingly.

Methods. Clarify the years during which the measurement process was conducted.

This information was added to the methods.

We expect that now you will find the article acceptable for publication.

Yours sincerely,

Ana Portugal Melo

Competing Interests: No competing interests were disclosed. 


\section{https://doi.org/10.5256/f1000research.120233.r126306}

(C) 2022 Campos Ferreira E. This is an open access peer review report distributed under the terms of the Creative Commons Attribution License, which permits unrestricted use, distribution, and reproduction in any medium, provided the original work is properly cited.

\section{Eugénio Campos Ferreira}

${ }^{1}$ CEB-Centre of Biological Engineering, Universidade do Minho, Braga, Portugal

2 LABBELS - Associate Laboratory, Guimarães, Portugal

An interesting opinion article on the performance and impact of the Biodata.pt, the Portuguese node of the ESFRI landmark ELIXIR, the European Research Infrastructure for life science. A significant coverage of indicators was compiled based on 3 frameworks: 20 out of 21 ESFRI indicators, 32 out of 58 OECD, ESFRI, OECD, RI-PATHS projects, 25 out of 102 RI-PATHS project indicators.

The main strengths of the article are related to the use of wide-spectrum frameworks created for the analysis of pan-European and global research infrastructures to a national (Portuguese) research Infrastructure, with ad hoc adaptations to reflect the national landscape and specificity of activities. The article also underlines the possibility of conducting a backward exercise able to prospect recommendations for the future, determine areas where impact aims are to be achieved, the indicators for each activity to be collected, as well as the methods for capturing should be documented.

A few remarks:

The title "Making European performance and impact assessment frameworks glocal" does not allow inferring the content of the typescript. Although the article is inserted in the ELIXIR gateway, I suggest that reference be made to the performance and impact of BioData.pt according to the addressed frameworks (ESFRI, OECD, RI-PATHS project).

One last note: the quote "Not everything that counts can be counted, and not everything that can be counted, counts", is frequently incorrectly attributed to Albert Einstein. Probably comes from a paper published in 1963 by the sociologist, William Bruce Cameron (Cullis $\left.2017^{1}\right)$.

\section{References}

1. Cullis J: Not everything that can be counted counts.....British Journal of Haematology. 2017; 177

(4): 505-506 Publisher Full Text

Is the topic of the opinion article discussed accurately in the context of the current literature?

Yes

Are all factual statements correct and adequately supported by citations? Yes

Are arguments sufficiently supported by evidence from the published literature? 
Yes

Are the conclusions drawn balanced and justified on the basis of the presented arguments? Yes

Competing Interests: No competing interests were disclosed.

Reviewer Expertise: Systems Biology; Bioinformatics; Research management and assessment

I confirm that I have read this submission and believe that I have an appropriate level of expertise to confirm that it is of an acceptable scientific standard.

Author Response 28 Jul 2022

\section{Ana Melo}

Dear Dr Ferreira,

Thank you for reading our article and making suggestions that contributed to its improvement.

The measures taken to address your concerns are described below your points:

The title "Making European performance and impact assessment frameworks glocal" does not allow inferring the content of the typescript. Although the article is inserted in the ELIXIR gateway, I suggest that reference be made to the performance and impact of BioData.pt according to the addressed frameworks (ESFRI, OECD, RI-PATHS project).

The authors have modified the title of the article.

One last note: the quote "Not everything that counts can be counted, and not everything that can be counted, counts", is frequently incorrectly attributed to Albert Einstein. Probably comes from a paper published in 1963 by the sociologist, William Bruce Cameron (Cullis $2017^{1}$ ).

The authors have confirmed and modified the attribution of this quote.

Yours sincerely,

Ana Portugal Melo

Competing Interests: No competing interests were disclosed. 
The benefits of publishing with F1000Research:

- Your article is published within days, with no editorial bias

- You can publish traditional articles, null/negative results, case reports, data notes and more

- The peer review process is transparent and collaborative

- Your article is indexed in PubMed after passing peer review

- Dedicated customer support at every stage

For pre-submission enquiries, contact research@f1000.com 